\title{
Nonsurgical Treatment of a Patient with Class III Malocclusion and Missing Maxillary Lateral Incisors: A Combined Orthodontic-Prosthodontic Approach
}

\author{
Sachin S Doshi, M Jayarama, Shashank Gaikwad, Amol Mhatre, Ravindranath
}

\begin{abstract}
Class III treatment is a considerable clinical challenge and commonly includes (a) growth modification involving a chincup to restrain mandibular growth or a facemask to protract the maxilla, (b) dentoalveolar compensation or camouflage involving dental extractions and (c) orthognathic surgery. Surgical treatment is the preferred and most stable treatment for adult patients with severe skeletal class III malocclusion. Patients with borderline dentoalveolar compensation who are not willing to accept the costs, risks and potential complications of surgery can sometimes be treated successfully with camouflage orthodontics. In more extreme cases, however, conservative orthodontic treatment may lead to adverse side effects, such as periodontal disease and root resorption as well as poor long-term stability. It is not clear which mechanics are most appropriate or which patients are most likely to benefit from an orthodontic approach to severe skeletal class III malocclusion. In this list of alternatives, orthodontic treatment is often seen as either a less-desirable alternative to surgery or a treatment reserved for milder skeletal problems. This report questions this hierarchy of treatment options.
\end{abstract}

Keywords: Class III, Camouflage, Mandibular prognathism, Multilooped archwire.

How to cite this article: Doshi SS, J ayarama M, Gaikwad S, Mhatre A, Ravindranath. Nonsurgical Treatment of a Patient with Class III Malocclusion and Missing Maxillary Lateral Incisors: A Combined Orthodontic-Prosthodontic Approach. J Contemp Dent 2012;2(2):57-63.

Source of support $\mathrm{Nil}$

Conflict of interest: None declared

\section{INTRODUCTION}

The frequency of class III malocclusions varies in different racial groups. The incidence among white people is 1 to $4 \%$; among black people, it is 5 to $8 \%$; in A sians, it ranges from 4 to $14 \% .{ }^{1}$ Skeletal class III problems are more common in the eastern countries than in the western world. M ore so, a high prevalence is seen in India particularly in the state of $\mathrm{K}$ erala, where there is a hereditary predilection for class III malocclusion and also because of high frequency of consanguineous marriage customs which are practiced here. $^{2}$

Patients with a class III malocclusion can have various combinations of skeletal and dental discrepancies. It is important to diagnose these to adequately treat the underlying cause or causes of the problem. Critical factors to be eval uated include the sagittal positions of the maxilla, the mandible, the maxillary and mandibular alveolar processes and vertical development. Guyer et al, for example, found that $57 \%$ of patients with a normal or prognathic mandible also had a deficient maxilla.

Class III treatment is a considerable clinical challenge and commonly includes (a) growth modification involving a chin-cup to restrain mandibular growth or a facemask to protract the maxilla, (b) dentoalveolar compensation or camouflage involving dental extractions and (c) orthognathic surgery. ${ }^{3}$ In this list of alternatives, orthodontic treatment is often seen as either a less-desirable alternative to surgery or a treatment reserved for milder skeletal problems. This report questions this hierarchy of treatment options.

\section{DIAGNOSIS AND ETIOLOGY}

A 22-year-old female presented for an orthodontic consultation (Figs 1A to I). Her chief complaint was the unesthetic appearance of her maxillary anterior teeth, which were behind the mandibular incisors and also missing teeth in the upper arch. She was allergic to ampicillin. Other than this, there were no significant findings in her medical history. In her dental history, she has had treatment for mandibular mid symphyseal fracture 1 year back which was managed with a conservative approach. She also had Ellis class 1 fractures of 26 and 35 which were restored with composite resin. Clinical examination also confirmed mandibular protrusion, maxillary retrusion and a concave profile with relatively large nose and a prominent chin. When she smiled, only half of the maxillary incisors were seen, and there was no gingival display. The patient had complete dentition including third molars except missing maxillary lateral incisors on both sides. She had a CO- CR discrepancy. There was a class I molar relationship on the right side and an end-on tendency on the left side with class I and end-on canine relation on right and left sides respectively in habitual occlusion. Overjet was negative, and there was $3.5 \mathrm{~mm}$ spacing in the mandibular anterior region and $3 \mathrm{~mm}$ spacing in the maxillary anterior region. Upper midline deviates to the right by $1 \mathrm{~mm}$ and lower 
midline was apparently normal. There was a shift of mandible to the right on opening. Despite the functional shift, no signs of TMD were detected. Oral hygiene maintenance was good.

Cephalometric analysis indicated features of skeletal crossbite (Table 1). The maxilla was significantly retrusive (SNA $=76$ ) relative to the anterior cranial base, while mandible was moderately protrusive $(S N B=83 \%)$ in $C O$, indicating a skeletal class III (ANB = - 70). The mandible show ed a forward and upward rotation and a hypodivergent skel etal pattern (SN-Go-Gn = 25\%).

\section{TREATMENT OBJECTIVES}

The treatment objectives included correcting the anterior crossbite, achieving normal overjet and overbite, achieving class I molar and canine relationships, eliminating the anterior functional shift and establishing canine guidance, improving facial appearance and correcting the appearance of the prognathic mandible, correcting the spacing in both arches, creation of space in the maxillary anterior region for prosthetic replacements of missing lateral incisors and correcting the maxillary midline deviation followed by replacement of missing lateral incisors.

\section{TREATMENT ALTERNATIVES}

Based on the objectives, two treatment options were proposed. To attain the overall objectives, combined surgical and orthodontic treatment with maxillary advancement and mandibular setback was proposed. It was explained to the patient and her parents why a more esthetic outcome could be expected with the surgical option. However, the risks and treatment expenses would be high. The second treatment option involved a nonsurgical approach with dentoalveolar compensations to camouflage the skeletal discrepancy. The patient chose the nonsurgical option and dentoalveolar compensation. The decision was based on the greater cost and the additional risks of the surgical procedure. For the replacement of missing lateral incisors in the maxillary arch consultation with a prosthodontist was done after which it was decided to replace them with a fixed partial denture as implant placement in this case was not a good option looking at the angulation in which the implant would have to be
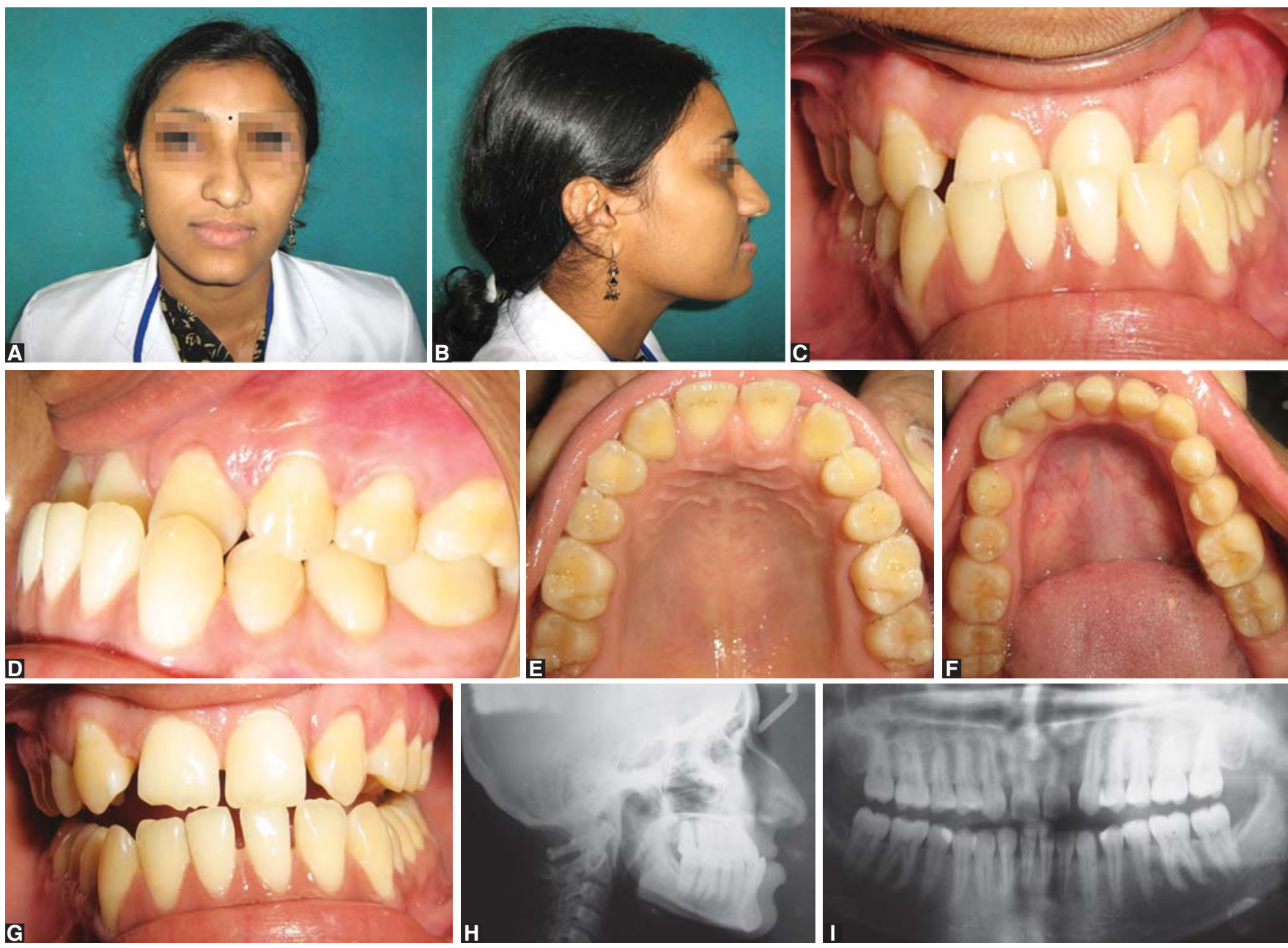

Figs 1A to I: A 22-year-old female patient with moderate dental and skeletal class III malocclusion before treatment 
placed, which would increase the chance of its failure. The patient agreed onto this decision.

\section{TREATMENT PLAN}

The treatment plan included banding all 4 first molars and all premolars; bonding both arches from canine to canine with Begg brackets* (TP Orthodontics). The intention of placing Begg brackets (unipoint contact) in this case was very clear as the main objective in this case was achieving tipping of the upper anterior teeth for the correction of anterior crossbite. Use of a preadjusted edgew ise appliance because of the presence of in built tip and torque would have limited the amount of tipping necessary in this case. Class III elastics and bite blocks to protract maxillary teeth and to open the bite temporarily were used.

\section{TREATMENT PROGRESS}

The maxillary and mandibular first molars were banded, along with the premolars and the maxillary and mandibular anterior segments were bonded. T reatment was started with 0.016 inch A ustralian Special Plus archwire in lower arch with $30^{\circ}$ anchor bend to open the bite (posterior bite blocks were used to open the bite to prevent debonding of the upper anterior brackets because of the crossbite). In the upper arch multiloop archwire as used in the original Begg technique was placed to flare the maxillary anterior teeth.
After the correction of the anterior crossbite space for replacement of lateral incisors was made by using open-coil springs. Lower arch spacing was closed simultaneously with the use of class III elastics. A fter class I canine and molar relationship was achieved on both sides uprighting of necessary teeth was done in the lower arch (Figs 2A to $\mathrm{C}$ ).

The treatment required 10 appointments over 11 months including 1 month of no change of wire or use of elastic or any mechanics which would cause tooth movement to hel $p$ stabilize the teeth after which the patient was debonded and referred to the prosthodontist. Tooth preparation and temporary restoration was done the same day of debonding to prevent any relapse tendency. Final fixed partial denture was placed after 3 days. No retainer was placed as the FPD would hold the teeth together and act as a retainer itself. Begg's wrapround retainer was used in the lower arch to prevent space reopening.

\section{TREATMENT RESULTS}

In general, the results for this patient were excellent, and her cooperation with appliances, intraoral elastics and oral hygiene was good. The posttreatment records show that facial esthetics improved (Figs 3 and 4). The mandible appears less prognathic, and the patient is pleased with her appearance. The midlines are coincident with each other and the midsagittal plane. The dental casts show a class I molar and canine relationship with normal overjet and

\begin{tabular}{|c|c|c|c|c|c|}
\hline \multicolumn{6}{|c|}{ Table 1: Cephalometric analysis } \\
\hline No. & & Mean & Kerala norm & Pre $\mathrm{Rx}$ & Post Rx \\
\hline 1 & SNA & $82^{\circ}$ & 84.140 & 760 & 760 \\
\hline 2 & SNB & 800 & $81.85^{\circ}$ & 83 & 830 \\
\hline 3 & ANB & 20 & $2.27^{\circ}$ & -70 & -70 \\
\hline 4 & U 1 to $N-A$ & $22^{\circ}$ & 27.440 & 380 & $47 \stackrel{0}{0}$ \\
\hline 5 & $\mathrm{U} 1$ to $\mathrm{N}-\mathrm{A} \mathrm{mm}$ & $4 \mathrm{~mm}$ & $7.46 \mathrm{~mm}$ & $12 \mathrm{~mm}$ & $17 \mathrm{~mm}$ \\
\hline 6 & $\mathrm{~L} 1$ to $\mathrm{N}-\mathrm{B}$ & 250 & $30.75^{\circ}$ & 190 & 150 \\
\hline 7 & $\mathrm{~L} 1$ to $\mathrm{N}-\mathrm{B} \mathrm{mm}$ & $4 \mathrm{~mm}$ & $7.5 \mathrm{~mm}$ & $6 \mathrm{~mm}$ & $3 \mathrm{~mm}$ \\
\hline 8 & Go-Gn to S-N & $32 \div$ & 27.91 & 250 & $27 \underline{0}$ \\
\hline 9 & $\mathrm{Occl}$ to $\mathrm{S}-\mathrm{N}$ & $14^{0}$ & 11.790 & 80 & 130 \\
\hline 10 & Po to N-B & & $1.06 \mathrm{~mm}$ & $5 \mathrm{~mm}$ & $3.5 \mathrm{~mm}$ \\
\hline 11 & Facial angle & $87.8^{\circ}$ & $85^{\circ}$ & $86 \div$ & $88^{\circ}$ \\
\hline 12 & Angle of convexity & 00 & $7.5^{\circ}$ & -190 & $-17^{\circ}$ \\
\hline 13 & $A B-N-P \circ g$ & -4.60 & -6.70 & 70 & 60 \\
\hline 14 & Mandibular plane angle & 21.90 & 26.70 & 240 & $23.5^{0}$ \\
\hline 15 & $Y$-axis & $59.4^{0}$ & 620 & 560 & $57 \stackrel{0}{0}$ \\
\hline 16 & Cant of occlusal plane & 9.30 & 110 & 3o & 60 \\
\hline 17 & $\mathrm{U} 1$ to $\mathrm{L} 1$ (interincisal) & $135.4^{\circ}$ & 119.690 & 1310 & 1250 \\
\hline 18 & L1 to occlusal plane & $14.5^{\circ}$ & $28.8^{\circ}$ & $16^{0}$ & 100 \\
\hline 19 & L1 to mandibular plane & $91.4^{\circ}$ & $103.8^{\circ}$ & 860 & $82.5^{0}$ \\
\hline 20 & U 1 to $A-P o$ line & $2.7 \mathrm{~mm}$ & $8.3 \mathrm{~mm}$ & $4 \mathrm{~mm}$ & $10 \mathrm{~mm}$ \\
\hline 21 & $\mathrm{~L} 1$ to $\mathrm{A}-\mathrm{Po}$ line & & & $9 \mathrm{~mm}$ & $6 \mathrm{~mm}$ \\
\hline 22 & U1- S-N & $102 \div(\mathrm{aft}$ & & 1130 & 1220 \\
\hline 23 & $\mathrm{H}$ line angle & 7 to $15^{\circ}$ & & 40 & 100 \\
\hline 24 & Nose tip to $\mathrm{H}$ line & $12 \mathrm{~mm}$ ( & & $17 \mathrm{~mm}$ & $14 \mathrm{~mm}$ \\
\hline 25 & Nasolabial angle & 90 to 11 & & 700 & $88^{\circ}$ \\
\hline
\end{tabular}


overbite. The final occlusion has acceptable interdigitation and canine guidance. A lthough the canine on left side was slightly less than class I this was an acceptable compromise as it would not move any forward because of the fixed partial denture.

The posttreatment panoramic radiograph shows that bone levels were maintained. The maxillary teeth were advanced slightly, and the mandibular incisors were retracted. The maxillary and the mandibular base skeletal base remained relatively stable. Comparison of the softtissue profile in the before and after cephalometric tracings shows improvement in the profile; the position of the upper lip is closer to the esthetic plane. Clinical examination of the mandibular position did not show that the mandible shifted backward, and there was no evidence of a centric relationcentric occlusion shift.

The posttreatment radiograph shows no evidence of root resorption or other pathology. The replacement of maxillary lateral incisors with fixed partial denture added more fullness to the upper lip which was lacking pretreatment. This also helped to mask the class III look and enhanced the soft tissue.

\section{DISCUSSION}

Case reports, al most by definition, document treatments that turned out well. Although they are interesting to read, it is
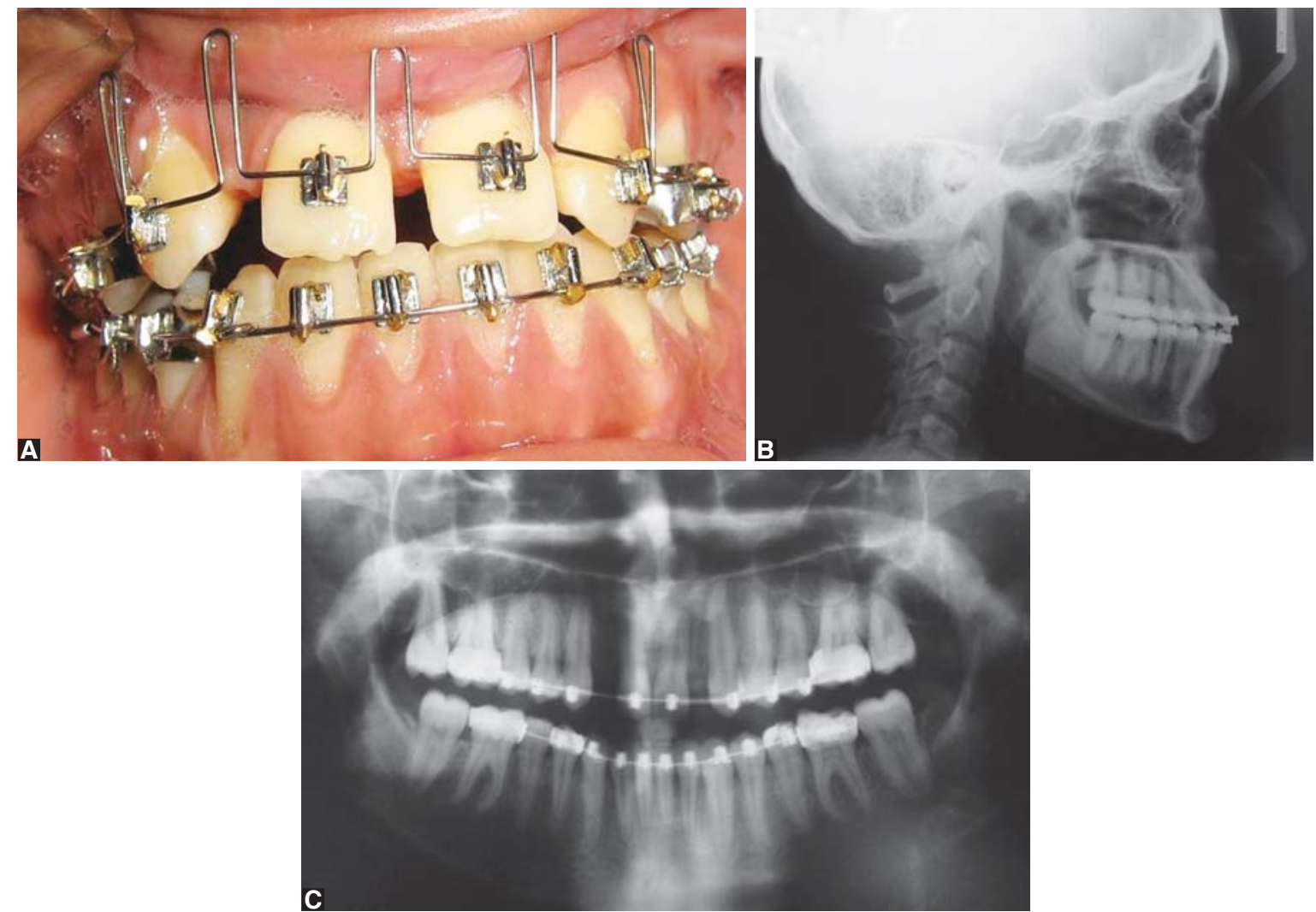

Figs 2A to C: Correction of anterior crossbite with multilooped archwire

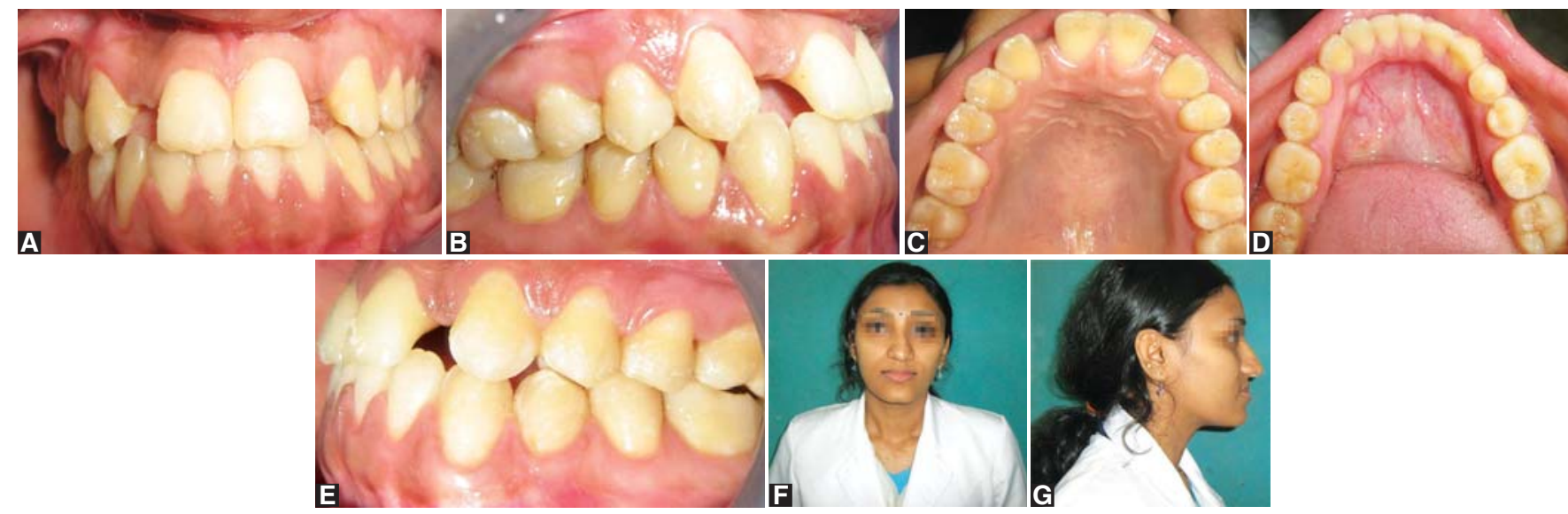

Figs 3 A to G: After debonding and opening the space for prosthetic replacement 
always difficult to know what, if anything can be inferred that will apply to future patients. In this report, however, there is a reasonably clear message about the compromise in orthodontic/surgical treatment planning. ${ }^{4}$

The skeletal class III is characterized by mandibular prognathism, maxillary deficiency and or combination of both. ${ }^{5-7}$ clinically, these patients exhibit a concave facial profile, a retrusive nasomaxillary area and a prominent lower third of the face. The upper arch is usually narrower than the lower and the overjet can range from reduced to reverse. ${ }^{8}$ The effects of environmental factors and oral function on the etiological factors of a class III malocclusion is not completely understood. However, there is a definite familial and racial tendency to mandibular prognathism ${ }^{9,10}$ for many class III malocclusions, surgical treatment can be the best alternative. A fter surgical correction of the skeletal discrepancy, the occlusion is usually finished to a class I relationship. However, if surgical treatment is not performed, and the final molar relationship is class III there are challenges specific to the static and functional class III occlusion that must be considered. ${ }^{11}$ Sometimes a class III relationship is caused by a forward shift of the mandible to avoid incisal interferences. This is a pseudo-class III malocclusion. In these cases it is important to establish the interocclusal relationship with the teeth in the retruded contact position. ${ }^{12}$

$M$ any would be comfortable with our original surgical recommendation and would consider orthodontic treatment alone a less desirable, somew hat overmatched alternative. It is probable that it would be labeled pejoratively as orthodontic camouflage, and our results would be dismissed as an interesting but isolated anomaly. Unfortunately, our degree of comfort is almost beside the point; we are not the ones ultimately faced with the burden-discomfort, risk and cost- of the surgery. Thus, it can be argued that for many patients the best strategy (i.e. the one with the greatest expected gain) would be orthodontic, rather than surgical, treatment. Stated simply, for some patients, the need for dramatic change is so great that the risk makes sense, but, for others with a lesser need, surgery's greater capacity for change might not be worth the risk.

The surgical correction of class III malocclusion can be undertaken in a variety of ways, e.g. a bilateral sagittal split osteotomy to retract the mandible or a Le Fort I procedure to advance the maxilla, or a combination of these. However, the associated surgical risks and complications must be considered, as well as the increased expense. If a nonsurgical treatment alternative can produce results comparable with
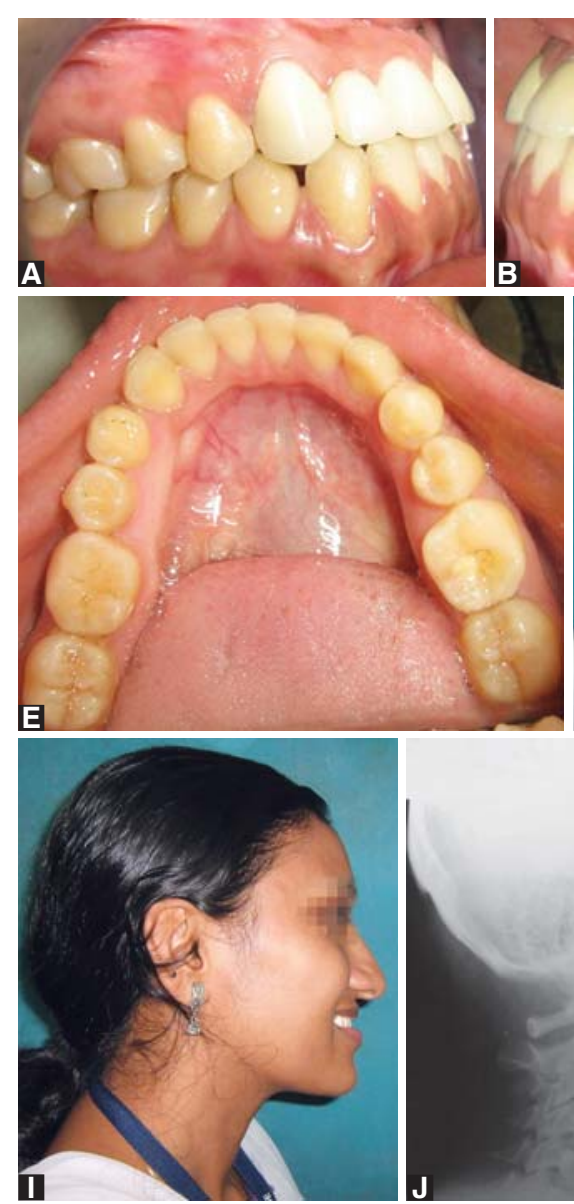
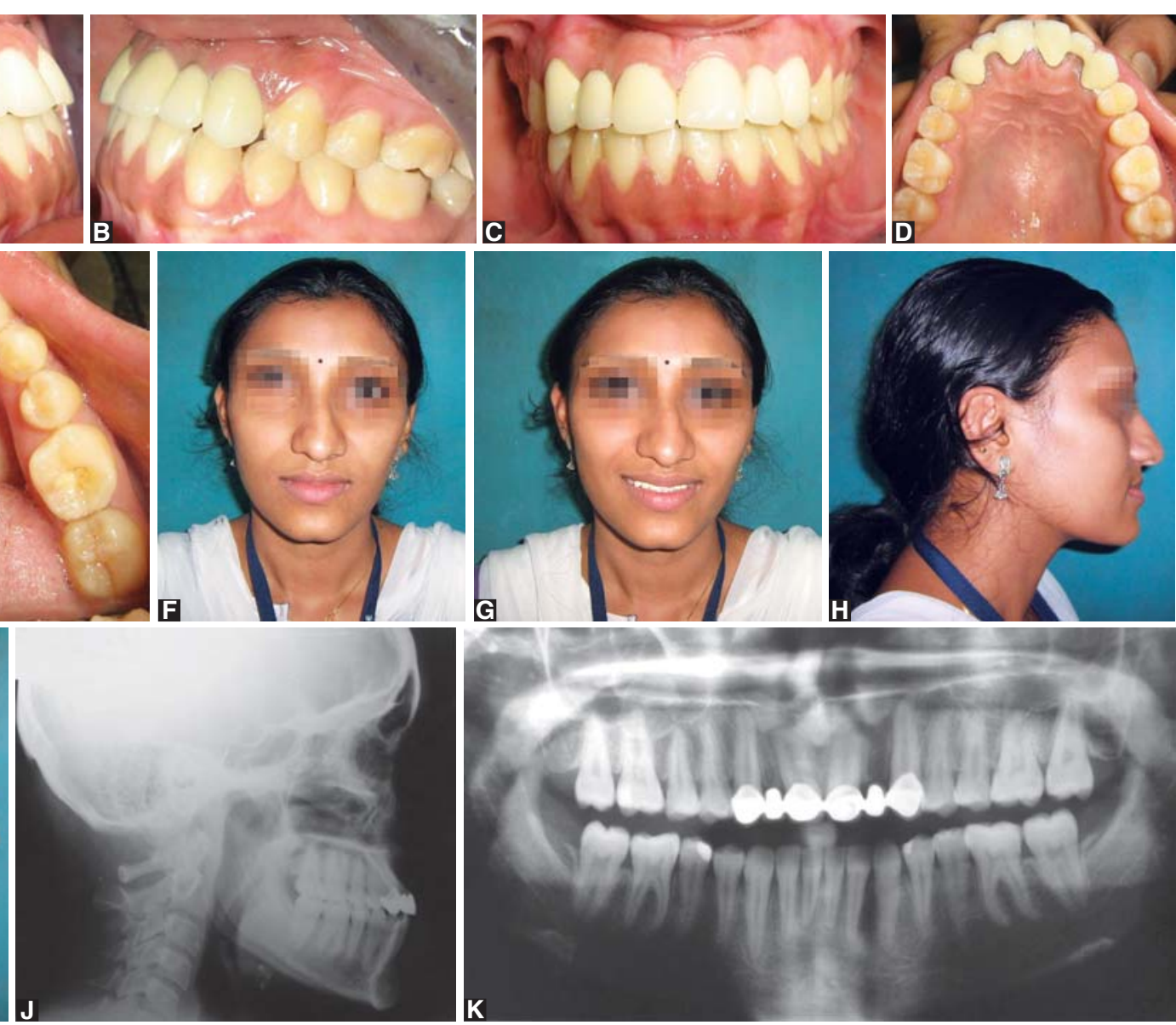

Figs 4A to $\mathrm{K}$ : After prosthodontic replacement of missing teeth 
those that could be achieved surgically, then it should be considered and can be the treatment of choice for some patients. ${ }^{13}$

The inclination of the incisors can determine whether an anterior crossbite can be successfully treated without surgery. Palatally inclined maxillary incisors can be moved labially and labially inclined mandibular incisors can be moved lingually - even to overcorrected positions - to establish a normal overjet. It was believed that acceptable facial profiles and functional occlusions could be achieved by treating this patient with protrusion of upper incisors and retrusion of lower incisors using fixed appliances without the need for orthognathic surgery.

W ith the goals of orthodontic treatment of harmonious facial esthetics and a functional occlusion, the soft tissue changes play an important role in evaluating treatment effects. The improvement of facial esthetics is therefore a major reason for seeking treatment. The soft tissue changes after orthodontic treatment are usually regarded as secondary to the underlying hard tissue alterations. ${ }^{14}$ Opinions differ about whether there is a definite correl ation between incisor change and soft tissue change. However, no matter which cephalometric analysis is used the balance and harmony of the facial profile should receive much attention. ${ }^{15-18}$

Positive overbite and overjet should help maintain the results. Light forces were used throughout the treatment to prevent or minimize apical root resorption on the mandibular incisors. The posttreatment radiographs show satisfactory root alignment of the mandibular incisors with no evident root resorption. This was a compromise treatment, with an excellent final result that has admirably met the patient's needs. The occlusion is functional and stable, and she has a pleasing smile. Her quality of life has been greatly improved, and surgery was avoided.

The patient was advised to undergo rhinoplasty and genioplasty after the orthodontic treatment to further improve her facial profile but she refused it.

\section{CONCLUSION}

The choice of treatment for any malocclusion must be tailored to each patient. All treatment possibilities, including those that are ideal and those that are a compromise, should be considered and explained to the patient, so that he or she can choose the most acceptable one. All problems perceived by a clinician might not be problems in the patient's eyes. The treatment that this patient received satisfied his needs, despite its limitations. B oth the patient and the orthodontist were satisfied with the results. The patient's chief concern was addressed and treated to his satisfaction, an esthetic smile was established, and the malocclusion was treated to a satisfactory and stable result.
On balance, although this treatment featured some interesting details, it is a more or less conventional approach to the orthodontic treatment of a moderately severe skel etal class III malocclusion. Its outcome reminds us of the potential of conventional orthodontic therapy to achieve adequate and acceptable results in many patients who might otherwise be consigned to surgery.

\section{REFERENCES}

1. N gan P. Treatment of class III malocclusion in the primary and mixed dentitions. In: B ishara SE, (Ed). Texbook of orthodontics. Philadel phia: W B Saunders 2001;375.

2. A handbook of cephalometric norms for Indian ethnic groups. E dited by D r K J yotindrakumar for Indian O rthodontic Society.

3. Proffit WR. Contemporary orthodontics (3rd ed). Saint L ouis: M osby 1999.

4. M oullas AT, Palomo JM, Gass JR, A mberman BD, White J, Gustovich D. C ase report nonsurgical treatment of a patient with a class III malocclusion. Am J Orthod Dentofacial Orthop 2006;129:S111-18.

5. Guyer EC, Ellis EE, M CNamara JA J r, Behrents RG. Components of class III malocclusion in juveniles and adolescents. A ngle Orthod 1986;56:7-30.

6. Sanborn RT. Differences between the facial skel etal patterns of class III malocclusion and normal occlusion. Angle Orthod 1955;25:208-22.

7. Williams S, A ndersen CE. The morphology of the potential class III skeletal pattern in the growing child. A m J Orthod Dentofac Orthop 1986;89:302-11.

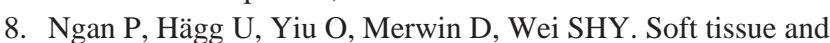
dentoskeletal profile changes associated with maxillary expansion and protraction headgear treatment. A m J Orthod D entofacial Orthop 1996;109:38-49.

9. Litton SF, A ckerman LV, Isaacson RJ, Shapiro B. A genetic study of class III malocclusion. A m J Orthod 1970;58:565-77.

10. Mossey PA. The heritability of malocclusion: Part 2. The influence of genetics in malocclusion. $\mathrm{Br}$ J Orthod 1999;26: 195-203.

11. Popp TW, Gooris CGM , Schur A J. Nonsurgical treatment for a class III dental relationship: A case report. A m J Orthod Dentofac Orthop 1993;103:203-11.

12. Clark JR, Hutchinson I, Sandy JR. Functional occlusion: Part II. The role of articulators in orthodontics. J Orthod 2001;28: 173-77.

13. Gelgör IE, Karaman AI. Nonsurgical treatment of class III malocclusion in adults: T wo case reports. J Orthodon 2005;32: 89-97.

14. Kerr WJS. Changes in soft tissue profile during the treatment of class III malocclusion. Br J Orthod 1987;14:243-49.

15. Holdaway RA. A soft tissue cephalometric analysis and its use in orthodontic treatment planning. Part II. A m J Orthod 1984;85: 279-93.

16. Oliver BM. The influence of lip thickness and strain on upper lip response to incisor retraction. A m J Orthod 1982;82: 141-49.

17. Udee DA. Proportional profile changes concurrent with orthodontic therapy. A m J Orthod 1964;50:421-34.

18. W isth PJ. Soft tissue response to upper incisor retraction in boys. BrJ Orthod 1974;1:199,204. 


\section{ABOUT THE AUTHORS}

\section{Sachin S Doshi (Corresponding Author)}

Senior Lecturer, Department of Orthodontics, MGM Dental College, Navi Mumbai, Maharashtra, India e-mail: sachin.doshibds@gmail.com

\section{Jayarama}

Retd. Professor and Head, Department of Orthodontics, Government Dental College, Calicut, Kerala, India

\section{Shashank Gaikwad}

Senior Lecturer, Department of Orthodontics, M GM Dental College Navi M umbai, M aharashtra, India

\section{Amol Mhatre}

Senior L ecturer, Department of Orthodontics, M GM Dental College Navi M umbai, M aharashtra, India

\section{Ravindranath}

Professor, Department of Orthodontics, MGM Dental College Navi M umbai, M aharashtra, India 